\title{
Mechanisms of Adsorption of Heavy Metal Cations from Waters by an Amino Bio-Based Resin Derived from Rosin
}

\author{
Wanting Huang ${ }^{1}$, Kaisheng Diao ${ }^{1}$, Xuecai Tan ${ }^{1}$, Fuhou Lei ${ }^{1}$, Jianxin Jiang 1,2, \\ Bernard A. Goodman ${ }^{1,3}$, Yahong $\mathrm{Ma}^{1}$ and Shaogang Liu ${ }^{1, * \mathbb{D}}$ \\ 1 Guangxi Key Laboratory of Chemistry and Engineering of Forest Products, Guangxi Colleges and \\ Universities Key Laboratory of Food Safety and Pharmaceutical Analytical Chemistry, \\ School of Chemistry and Chemical Engineering, Guangxi University for Nationalities, \\ Nanning 530008, China; hwt0506@126.com (W.H.); Diaokaisheng2010@163.com (K.D.); \\ tanxc118@163.com (X.T.); leifuhou@163.com (F.L.); jiangjx@bjfu.edu.cn (J.J.); \\ bernard_a_goodman@yahoo.com (B.A.G.); myh105060@163.com (Y.M.) \\ 2 Department of Chemistry and Chemical Engineering, MOE Engineering Research Center of Forestry \\ Biomass Materials and Bioenergy, Beijing Forestry University, Beijing 100083, China \\ 3 College of Physical Science and Engineering, Guangxi University, Nanning 530004, China \\ * Correspondence: liushaogang2005@163.com; Tel.: +86-0771-3267019
}

Received: 1 February 2019; Accepted: 19 May 2019; Published: 3 June 2019

\begin{abstract}
Rosin derived from conifer trees is used as the basis for a novel environmentally-friendly adsorbent prepared from a sustainable resource. After treatment with ethylenediamine, ethylenediamine rosin-based resin (EDAR) is produced, which possesses cation exchange capacity that is comparable to that of the best commercial synthetic resins. This is demonstrated by its application to the removal of $\mathrm{Pb}, \mathrm{Cd}$, and $\mathrm{Cu}$ from water, in single and multicomponent systems. Maximum uptake was obtained at $\mathrm{pH} 5$ and in the order $\mathrm{Pb}(\mathrm{II})>\mathrm{Cd}(\mathrm{II})>\mathrm{Cu}$ (II). The maximum adsorption of $\mathrm{Pb}$ was $\sim 1.8 \mathrm{mmol} / \mathrm{g}$, but the adsorption process resembled the Freundlich isotherm, whereas the adsorption of $\mathrm{Cd}$ (II) and $\mathrm{Cu}$ (II) followed the Langmuir isotherm. In the multicomponent systems, there was direct competition between $\mathrm{Pb}$ and $\mathrm{Cd}$ for sorption sites, whereas the results with $\mathrm{Cu}$ indicated it had a preference for different types of sites compared to $\mathrm{Pb}$ and $\mathrm{Cd}$. The EDAR resin could be efficiently regenerated and used repeatedly with only a small decrease in performance. Characterization of EDAR, and investigations of its adsorption mechanisms using physical, spectroscopic, and theoretical techniques, including fourier transform infrared spectroscopy (FTIR), ${ }^{13} \mathrm{C}$ nuclear magnetic resonance $\left({ }^{13} \mathrm{C}\right.$ NMR), scanning electron microscope (SEM), Brunauer Emmett Teller (BET) method, elemental analysis, thermogravimetric analysis (TGA), and molecular dynamics calculations, showed that amino groups have a critical role in determining the cation adsorption properties. We conclude that this new adsorbent derived from an abundant natural material has the potential to make valuable contributions to the routine removal of heavy metal ions (HMs) from drinking water and wastewater.
\end{abstract}

Keywords: aminated rosin-based resin; heavy metals; adsorption mechanism; density-functionaltheory; interaction model

\section{Introduction}

Water pollution by toxic heavy metal ions (HMs) is a cause of great global concern, because of their toxicity, non-biodegradability, and possible carcinogenicity [1,2]. Thus strict regulations and guidelines for the discharge of HMs have been established or recommended in many countries in response to public demands for clean water with extremely low levels of HMs. Considerable attention has been 
focused on the development of cost-effective procedures for HMs removal, and adsorption is generally considered to be an effective green separation technology, because of its simplicity, ability to reuse adsorbents, high selectivity, and high adsorption capacity. Numerous adsorbents, such as activated carbon, mesoporous silica, clay minerals, biosorbents, and polymeric resins have been used for the removal of HMs from water [3-8]. Among these adsorbents, synthetic polymers, particularly polyamine resins, have important advantages, which include high adsorption capacity, ready modification with functional groups, excellent stability, and easy regeneration [9]. Various chelating resins have been prepared by polymerization using cross-linkers, such as divinylbenzene, but these can then lead to secondary pollution if they subsequently break down $[10,11]$, and in recent years more efforts have been paid to the development of adsorbents that are environmentally friendly, low-cost, and from renewable resources.

Rosin is an abundantly available natural product obtained from pine trees, which contains various isomerized acids $\left(\mathrm{C}_{19} \mathrm{H}_{29} \mathrm{COOH}>90 \%\right)$ and some neutral components [12,13]. Its structure, based on phenanthrene, has excellent rigidity and improves resin structures when combined with synthetic polymers. Rosin-derived polymers have been synthesized for use in molecular separation and industrial synthesis [14]. Consequently, rosin has received increasing attention as a raw material for the synthesis of some new polymers with specific chemical structures and valuable properties $[15,16]$. However, despite great effort in developing applications using natural rosin and its derivatives, there is still very little literature on the use of rosin-based resins for the removal of HMs from drinking water and wastewaters.

For improved design of more effective adsorbents for the removal of HMs from water, it is important to understand the nature of their interactions. In the present work, products were characterized using various spectroscopic techniques, supported by theoretical calculations [17-19]. Quantum chemical calculations using the Density-Functional-Theory (DFT) provide an insight into interaction models, structures, and the binding abilities of various functional groups in the adsorbents towards HMs [20-22], and thus provide qualitative knowledge of adsorption mechanisms for the removal of HMs from water.

In this study, a novel ethylenediamine rosin-based resin (EDAR) was synthesized using free radical polymerization technology, and its performance evaluated for the removal of $\mathrm{HM}$ cations from aqueous solutions. Its effectiveness in removing $\mathrm{Pb}(\mathrm{II}), \mathrm{Cd}(\mathrm{II})$, and $\mathrm{Cu}$ (II) from water was assessed with single and multi-component systems, and compared with equivalent measurements with the initial rosin-based resin. Further insight into the adsorption behavior was obtained from thermodynamic and kinetic analyses of results from batch and fixed column systems.

\section{Experimental Section}

\subsection{Materials}

Natural rosin was collected from Wuzhou, Guangxi, China. Acrylic acid, maleic anhydride, glycol, methylacrylic acid, 2,2'-azoisobutyronitrile (AIBN), $\mathrm{Pb}\left(\mathrm{NO}_{3}\right)_{2}, \mathrm{Cu}\left(\mathrm{NO}_{3}\right)_{2} \cdot 3 \mathrm{H}_{2} \mathrm{O}, \mathrm{Cd}\left(\mathrm{NO}_{3}\right)_{2}$, $\mathrm{MgCl}_{2}, \mathrm{HNO}_{3}$, and $\mathrm{Ca}\left(\mathrm{NO}_{3}\right)_{2}$.were purchased from Sinopharm Chemical Reagent Co., Ltd, Shanghai, China. Synthetic humic acid (HA) was purchased from Aldrich Chemical Company, Milwaukee, WI, USA. All other chemicals were of analytical grade and all solutions were prepared with ultrapure water produced by a Milli-Q system (Advanatge A10, Millopore, Billerica, MA, USA). The main physiochemical properties of the commercial adsorbents used in this study are presented in Supporting Information (SI) Table S1.

\subsection{Resin Synthesis and Characterization}

The cross-linking agent, ethylene glycol maleic rosinate acrylate (EGMRA) was synthesized via the Diels-Alder addition of natural rosin and maleic anhydride, and subsequent esterification with ethylene glycol and acrylic acid, according to our previous study [14]. EDAR was then synthesized as described 
in SI Text S1 and Scheme 1, where methylacrylic acid was used as the monomer, ethylene glycol maleic rosinate acrylate as the cross-linking reagent, peanut oil as the porogen, 2, 2'-azobisisobutyronitrile as the initiator, and ethylenediamine as the modifier. The final product was dried under vacuum at $50{ }^{\circ} \mathrm{C}$ for $8 \mathrm{~h}$ before characterization as described in SI Text S2, and used in absorption studies.

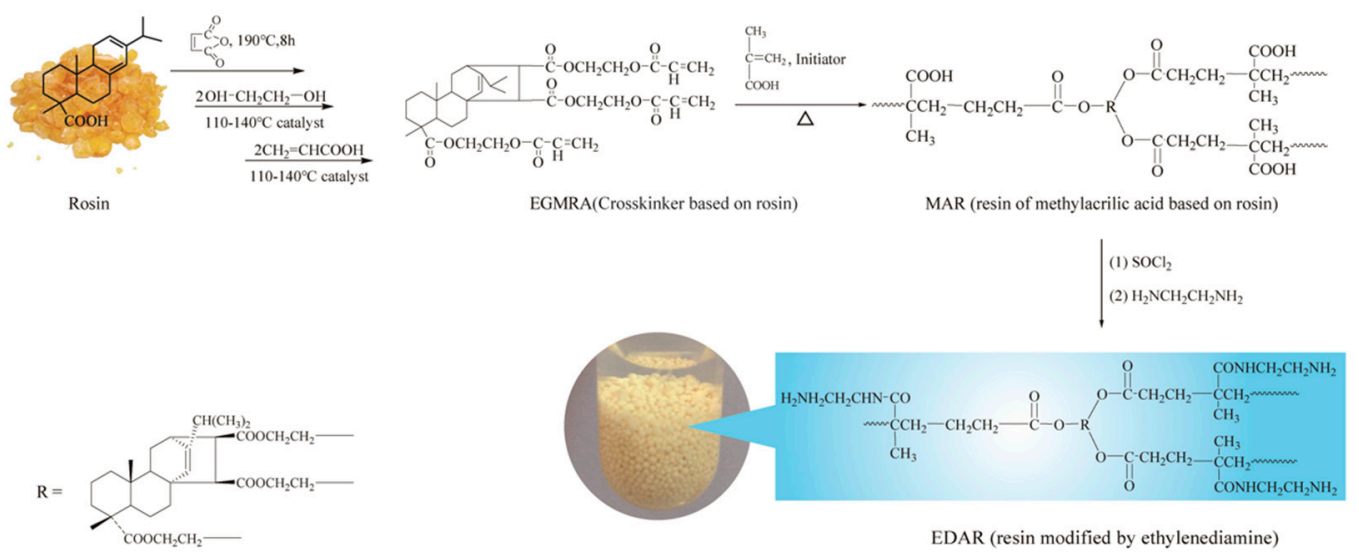

Scheme 1. Illustration of the strategy of synthesis of aminated rosin-based resin (EDAR).

\subsection{Batch Adsorption Studies}

All experiments were performed at $25^{\circ} \mathrm{C}$ in the dark and conducted in $150 \mathrm{~mL}$ conical flasks (containing $50 \mathrm{~mL}$ of solutions), which were shaken at $150 \mathrm{rpm}$ for $24 \mathrm{~h}$ to ensure equilibrium. After a preliminary experiment to determine the optimum adsorbent dosage for high removal efficiency (SI Figure S1), batch experiments were employed to study the effects of various operating parameters, such as solution $\mathrm{pH}$, ionic strength, co-existing ions, humic acid, and contact time, as well as the kinetics, isotherms, and thermodynamics of HMs adsorption. To investigate the adsorption performance of EDAR in natural waters, three samples from tap water, Yongjiang River, and Xiangsi Lake in Nanning were compared, and their characteristics are listed in SI Table S2. These water samples were filtered through a Millipore cellulose membrane filter $(0.45 \mu \mathrm{m}$ pore size), then their $\mathrm{pH}$ values were adjusted to 5.0 , and finally spiked with $0.5 \mathrm{mM} \mathrm{Pb}(\mathrm{II}), \mathrm{Cd}(\mathrm{II})$, or $\mathrm{Cu}(\mathrm{II})$. All experiments were performed in duplicate.

\subsection{Adsorption Dynamics, Regeneration and Adsorbent Stability}

Solutions containing HMs were passed upwards through a glass column $(\Phi 10 \mathrm{~mm} \times 500 \mathrm{~mm})$ packed with $1.2 \mathrm{~g}$ EDAR with a flow rate of $2.0 \mathrm{~mL} / \mathrm{min}$, and their concentrations at the column outlet were measured at various time intervals. Resin that had been used for adsorption of $\mathrm{Pb}$ (II) was regenerated with $0.1 \mathrm{M} \mathrm{HCl}$ solution, followed by $0.2 \mathrm{M} \mathrm{NaHCO}_{3}$ (for activation of the resin) at $25^{\circ} \mathrm{C}$, because of its weakly basic nature. The regenerated resin was washed with water until neutral $\mathrm{pH}$ prior to reuse. The adsorption-desorption cycle of $\mathrm{Pb}(\mathrm{II})$ was repeated 5 times to evaluate regeneration of the adsorption capacity.

\subsection{Analysis Procedures}

The concentrations of $\mathrm{Pb}(\mathrm{II}), \mathrm{Cd}(\mathrm{II})$, and $\mathrm{Cu}(\mathrm{II})$ in the residual solutions were determined by inductively coupled plasma atomic emission spectroscopy (ICP-AES) (Thermo, Franklin, MA, USA). Amounts of HMs adsorbed were calculated as the differences between the initial and residual concentrations (SI Text S3). Resin stability was assessed by shaking EDAR (100 mg) in water (200 mL) for $24 \mathrm{~h}$ at $30^{\circ} \mathrm{C}$ and $\mathrm{pH}$ 6.0, then measuring the benzene series compounds (chlorobenzene, toluene, styrene, and xylene) and methacrylic acid using a gas chromatography-tandem mass spectrometer (GC-MS/MS, Bruker, Fremont, CA, USA). 


\subsection{Quantum Chemistry Calculations}

All calculations were performed with the Gaussian 09 package (Gaussian, Inc., Wallingford, CT, USA) using dimers with different functional groups (e.g., methacryloyl, ethylenediamine or carboxylic) to simulate the donor moiety of the polymer chains [23]. All geometries were confirmed by frequency analysis that the ground state configuration and zero-point correction value were obtained. Various possible adsorption models of the complex system were explored and compared, but only those with the lowest energies are presented. Descriptions of the quantum chemistry calculations and the interaction energies $(\Delta \mathrm{E})$ are presented in detail in SI Text S4.

\section{Results and Discussion}

\subsection{Characterization of EDAR}

The resins were characterized by FTIR, ${ }^{13} \mathrm{C}$ NMR, SEM, BET, elemental analysis, and TGA. SEM images of EDAR showed that the EDAR samples are spherical beads (Figure 1a). In the IR spectra (Figure 1b), the characteristic peaks of amide I at $1640 \mathrm{~cm}^{-1}$ and amide II at $1547 \mathrm{~cm}^{-1}$ were present in EDAR but not in the resin (MAR) that was not treated with ethylenediamine. Some residual carboxylic acid groups characterized by peaks at around $3,500 \mathrm{~cm}^{-1}$ and $1,719 \mathrm{~cm}^{-1}$ remained in EDAR, which showed that only the $\mathrm{H}$-bonded hydroxyl groups with a peak at $\sim 3,250 \mathrm{~cm}^{-1}$ were modified by ethylenediamine. The ${ }^{13} \mathrm{C}$ NMR spectra (Figure 1c) also confirmed the presence of an amide linkage at $186.5 \mathrm{ppm}$ in EDAR along with a peak for the carbonyl carbon at $180 \mathrm{ppm}$, which also occurred in MAR. Finally, elemental analyses showed that the $\mathrm{N}$ content of EDAR ( $5.41 \%$ by mass) was much higher than that of MAR ( $0.15 \%$ by mass), thus further confirming that amine groups were successfully grafted onto the linking units of MAR-it was calculated that $1 \mathrm{~g}$ EDAR contained $1.83 \mathrm{mmol}$ amine groups. $\mathrm{N}_{2}$ adsorption-desorption isotherms for EDAR displayed a Type II profile according to the IUPAC classification with a specific area of $13.6 \mathrm{~m}^{2} / \mathrm{g}$ (SI Figure S2) [24]. The pore diameter and total pore volume were $6.44 \mathrm{~nm}$ and $0.017 \mathrm{~cm}^{3} / \mathrm{g}$, respectively, and their distribution curve showed a concentration of diameters of $\sim 50 \mathrm{~nm}$. The TGA curve for EDAR (Figure 1d) showed that the resin was stable to $160{ }^{\circ} \mathrm{C}$ in air, which is adequate for use in water treatment, where elevated temperatures are not involved.
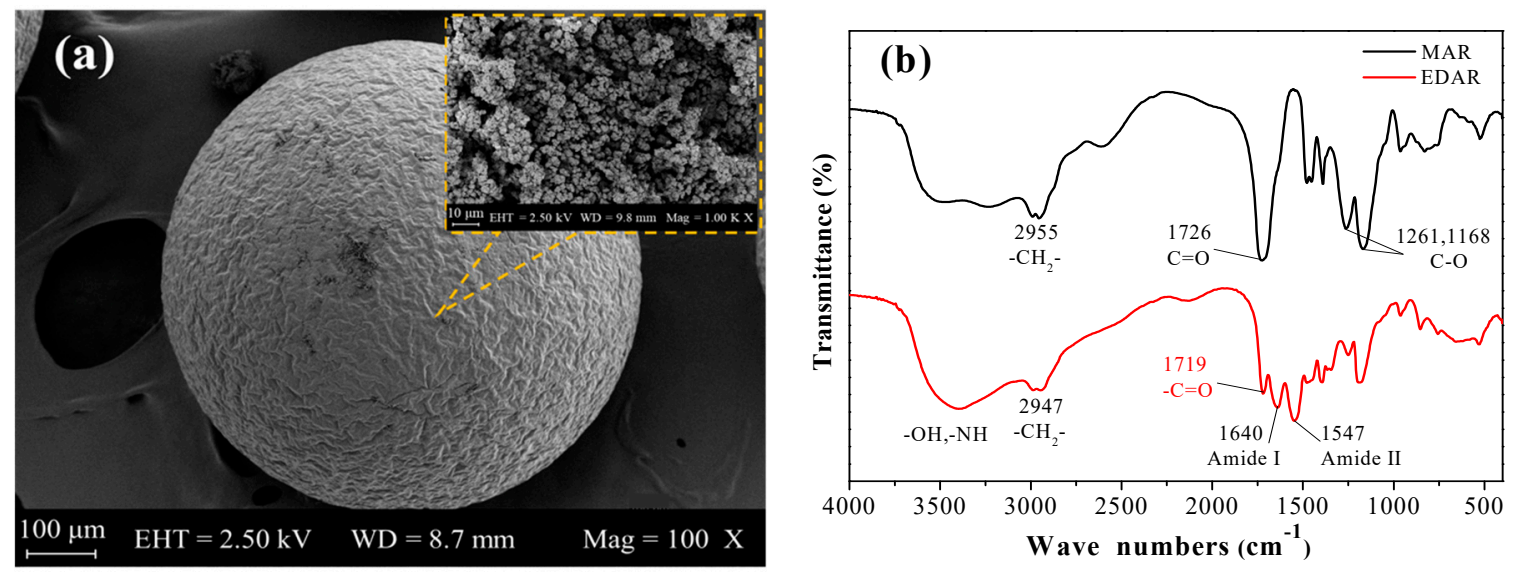

Figure 1. Cont. 

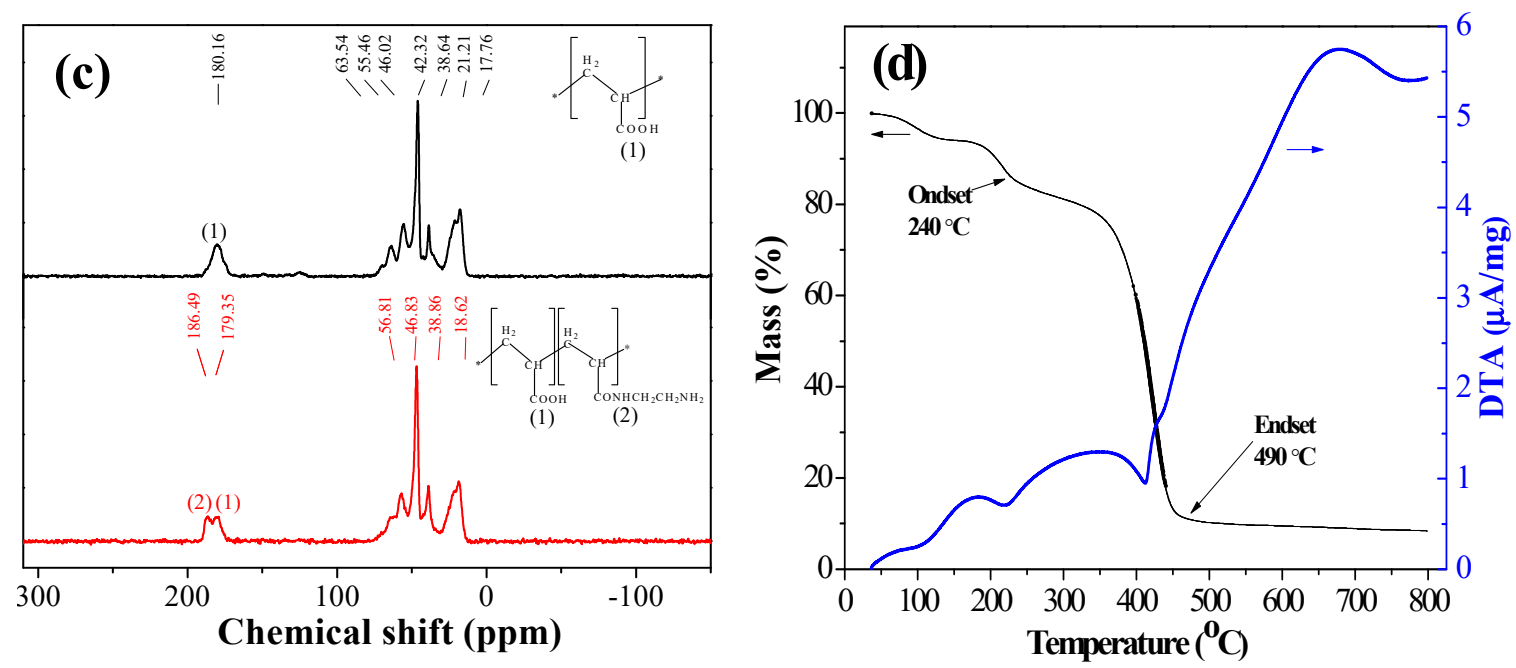

Figure 1. (a) SEM image of EDAR with different magnifications, (b) FTIR spectra of MAR and EDAR, (c) ${ }^{13} \mathrm{C}$ NMR spectra of MAR and EDAR using $\mathrm{CD}_{3} \mathrm{COOD} / \mathrm{D}_{2} \mathrm{O}$ as solvent, and (d) TGA curves for EDAR for the temperature range $40-800{ }^{\circ} \mathrm{C}$.

\subsection{Comparison of Adsorption Capacities of EDAR and Various Commercial Adsorbents}

The adsorption capacities of EDAR and MAR were compared with those of several commercial resins and granular activated carbon (GAC), which are currently used commercially for the removal of HMs from waters (SI Figure S3). The adsorption capacities of EDAR for $\mathrm{Pb}(\mathrm{II}), \mathrm{Cd}(\mathrm{II})$, and $\mathrm{Cu}$ (II) were much higher than those of MAR, which confirms that incorporation of aminated moieties greatly improves the HM adsorption properties, and thus implies that adsorption involves chelation and is not simply electrostatic attraction. Furthermore the adsorption capacities of EDAR for the HMs at $\mathrm{pH}$ 5.0 were similar to those of the resins D113 and IRC748, and higher than the resins DAX-8, IRA410, L-493, XAD-1180, XAD-4, and GAC. EDAR is a promising adsorbent for the removal of HMs from water, compared to the currently used petroleum-derived resins.

\subsection{Single and Multi-Component Adsorption Isotherms}

The adsorption isotherms for $\mathrm{Pb}$ (II), $\mathrm{Cd}$ (II) and $\mathrm{Cu}$ (II) ions on EDAR in single, binary, and ternary systems are shown in Figure 2. It is noted that the amounts of adsorbed Cd(II) decreased with the increasing $\mathrm{Pb}$ (II) and $\mathrm{Cu}$ (II) concentrations above $0.1 \mathrm{mM}$ in both binary and ternary systems. For single element systems, the experimental data were analyzed by the Langmuir and Freundlich isotherms (SI Text S5), and the parameters calculated from these models are listed in SI Table S3. Adsorption of $\mathrm{Pb}(\mathrm{II})$ is well described by the Freundlich model with high correlation coefficients $\left(R^{2}\right)$, whereas the adsorption of $\mathrm{Cd}(\mathrm{II})$ and $\mathrm{Cu}$ (II) were better fitted by the Langmuir model. This result suggests that some $\mathrm{Pb}(\mathrm{OH})_{2}$ species start to form on the surface of the adsorbent at this $\mathrm{pH}$, whereas with $\mathrm{Cd}$ and $\mathrm{Cu}$ the adsorption of monolayers is consistent with their chelation to functional groups on the surface of the resin. The theoretical capacities for $\mathrm{Pb}(\mathrm{II}), \mathrm{Cd}(\mathrm{II})$, and $\mathrm{Cu}(\mathrm{II})$ on EDAR are about 1.8, 1.32, and $1.12 \mathrm{mmol} / \mathrm{g}$, respectively, and are comparable to or greater than those of other bio-polymers in previous publications, which are listed in Supplementary Information Table S4. 


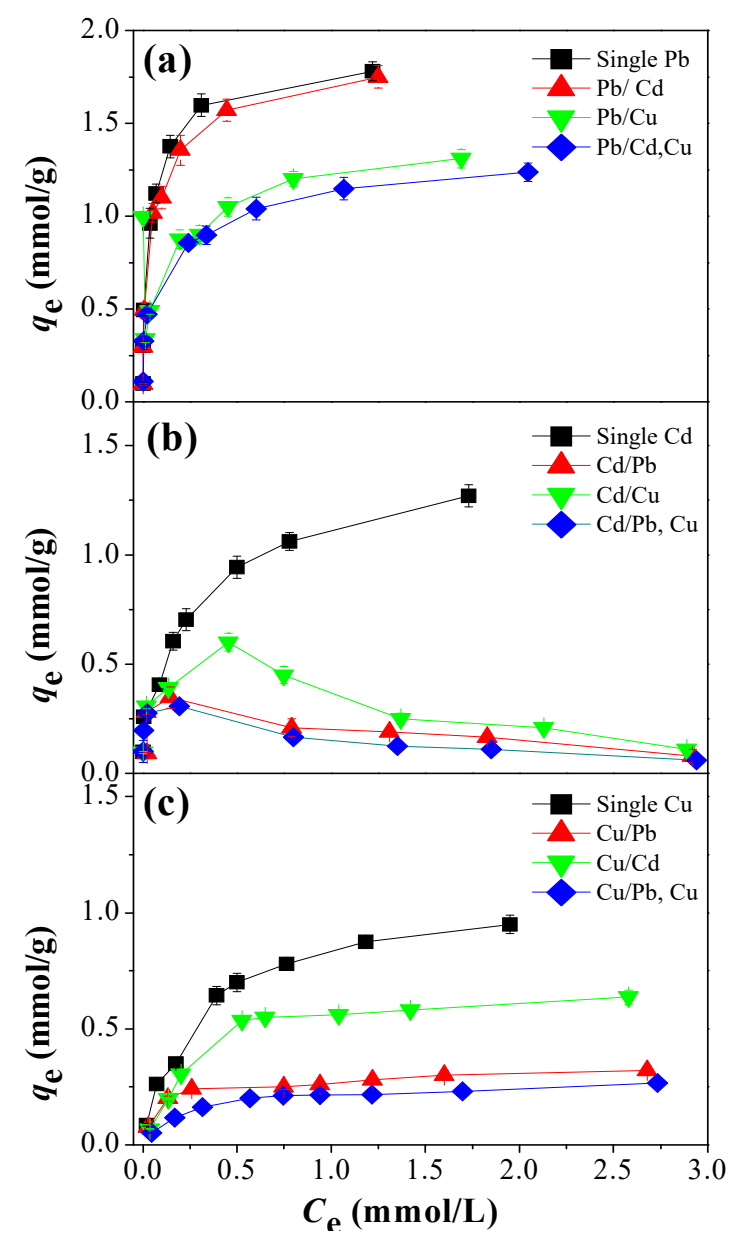

Figure 2. Adsorption isotherms for (a) $\mathrm{Pb}(\mathrm{II}),(\mathbf{b}) \mathrm{Cd}(\mathrm{II})$, and (c) $\mathrm{Cu}(\mathrm{II})$ on EDAR in single, binary, and ternary systems. Experimental conditions: $[\mathrm{HMs}] \mathrm{o}=0.1,0.3,0.5,0.8,1.0,1.5,2.0$, and $3.0 \mathrm{mM}$; [EDAR dosage $]=1.0 \mathrm{~g} / \mathrm{L}$; contact time $=24 \mathrm{~h} ; \mathrm{pH} 5.0 ; 25^{\circ} \mathrm{C}$.

Adsorption isotherms for HMs under competitive conditions are also shown in Figure 2. Uptake of the strongly adsorbed $\mathrm{Pb}$ (II) was unaffected by the presence of $\mathrm{Cd}$ (II), but compared to the single element was lowered by about $30 \%$ by the presence of an equivalent amount of $\mathrm{Cu}$ (II) in both binary and ternary systems. Furthermore, compared to the single element system, $\mathrm{Cu}(\mathrm{II})$ uptake was lowered by about $35 \%$ by the presence of an equivalent amount of $\mathrm{Cd}(\mathrm{II})$, and by $\sim 65 \%$ by an equivalent amount of $\mathrm{Pb}$ (II) in both binary and ternary systems. The relationships for $\mathrm{Cd}(\mathrm{II})$, however, were more complex, and actually showed a decrease in the amounts adsorbed with increasing Cd(II) contents above $0.5 \mathrm{mmol} / \mathrm{L}$ when equivalent amounts of $\mathrm{Pb}(\mathrm{II})$ and/or $\mathrm{Cu}$ (II) were also present.

To analyze the nature of competition among $\mathrm{Pb}(\mathrm{II}), \mathrm{Cd}(\mathrm{II})$, and $\mathrm{Cu}(\mathrm{II})$, the Langmuir competitive isotherm (LCM) model [25], which describes adsorption of component $i$ in the presence of component $j$ (SI Text S6), was applied to the binary and ternary adsorption equilibrium data:

$$
q_{\mathrm{e}, \mathrm{i}}=q_{\mathrm{m}, \mathrm{i}} \mathrm{K}_{\mathrm{L}, \mathrm{i}} \mathrm{C}_{\mathrm{e}, \mathrm{i}}\left(1+\sum_{\mathrm{j}=1}^{\mathrm{n}} \mathrm{K}_{\mathrm{L}, \mathrm{i}} \mathrm{C}_{\mathrm{e}, \mathrm{j}}\right)^{-1}
$$

where $\mathrm{K}_{\mathrm{L}, \mathrm{i}}$ is the individual Langmuir isotherm constant for each component. $q_{\mathrm{m}, \mathrm{i}}$ and $C_{\mathrm{e}, \mathrm{i}}$ are the maximum adsorption capacities and equilibrium concentrations in the mixture of solutes. The LCM model was able to fit the $\mathrm{Pb}(\mathrm{II})$ and $\mathrm{Cu}$ (II) adsorption data in the binary and ternary systems $\left(R^{2}>0.998\right)$, but not that of $\mathrm{Cd}(\mathrm{II})$ under competitive adsorption conditions (SI Figure S4). 


\subsection{Effect of Adsorption Parameters on HMs Adsorption}

Various conditions for the adsorption of HMs on EDAR were also investigated, and are described in this section.

\subsection{1. $\mathrm{pH}$}

There was a general increase in adsorption with increasing solution $\mathrm{pH}$ up to $\mathrm{pH} 5$ (SI Figure S5a), and the adsorption amounts for $\mathrm{Pb}(\mathrm{II}), \mathrm{Cd}(\mathrm{II})$, and $\mathrm{Cu}$ (II) containing $0.5 \mathrm{mmol} / \mathrm{L}$ were $0.49,0.40$, and $0.34 \mathrm{mmol} / \mathrm{g}$, respectively. With each HM, the HM adsorption capacity of EDAR showed little change in the $\mathrm{pH}$ range 3.0-5.0, but there was an appreciable decrease when the $\mathrm{pH}$ was $<3.0$. The reason is successful competition between protons and HMs for the surface sites at highly acidic $\mathrm{pH}$. There was no further increase in adsorption at $\mathrm{pH}$ values $>5.0$, and with $\mathrm{Cu}(\mathrm{II})$ there was an appreciable decrease, presumably a consequence of hydrolysis reactions [26], which lead to precipitation of metal hydroxides at higher $\mathrm{pH}$ [18]. Thus, a $\mathrm{pH}$ of 5.0 was selected for all of the following adsorption experiments. The curves for the zeta potentials for both MAR and EDAR are presented as SI Figure S6. The isoelectric point ( $\mathrm{pH}$ at which the net surface charge on the particle is zero) of MAR was approximately $\mathrm{pH} 4.7$ whereas that of EDAR was nearly $\mathrm{pH} 10$. Thus, although adsorption on MAR may be mainly electrostatic in nature, with EDAR electrostatic interactions are relatively minor, and complexation represents the main adsorption reaction.

\subsubsection{Salinity and Coexisting Compounds}

Natural waters invariably contain various anions and cations that could potentially interfere with the adsorption of the HMs, either by competing with them for sites on the adsorbent, or competing with the adsorbent for the HM ions. Therefore, we also investigated the effects of $\mathrm{Na}(\mathrm{I}), \mathrm{Mg}(\mathrm{II})$, and $\mathrm{Ca}(\mathrm{II})$ cations, plus synthetic humic acid as a model anion, on the HM adsorption. Only slight decreases in adsorption of HMs were observed when $\mathrm{NaCl}$ concentrations were increased from 0 to $20 \mathrm{mM}$ (SI Figure S5b), whilst increasing $\mathrm{Mg}$ and $\mathrm{Ca}$ in the 0 to $19 \mathrm{mM}$ concentration range resulted in small progressive decreases in HMs adsorption (SI Figure S5c). Furthermore, there was little effect of HA at concentrations of 0 to $0.5 \mathrm{mg} / \mathrm{L}$ (SI Figure S5d).

\subsubsection{Adsorption Kinetics}

Adsorption of HMs on EDAR showed an initial rapid increase, but then slowed as equilibrium was approached (after about $360 \mathrm{~min}$ ) (SI Figure S5e and Text S8). The adsorption kinetics were fitted well with the pseudo-second-order model with high correlation coefficients $\left(R^{2}>0.99\right)$ (SI Table S5 and Figure S5f). The plots of $q_{\mathrm{t}}(\mathrm{mg} / \mathrm{g})$ versus $\mathrm{t}^{0.5}$ for the intra-particle diffusion model were not linear (SI Figure S5g), although they could be separated into two linear regions. This suggests that there is an initial rapid step, followed by a slower step based on chelation, which involves some structural rearrangement.

\subsubsection{Temperature and Thermodynamics}

Thermodynamic parameters (SI Text S7) for HMs adsorption on EDAR were obtained from experiments performed at three different temperatures $\left(25,35\right.$, and $\left.45^{\circ} \mathrm{C}\right)$ (SI Figure S5h). These show that the amount of adsorbed HMs increased with increasing temperature from 25 to $45^{\circ} \mathrm{C}$. Standard enthalpy change $\left(\Delta H^{\circ}\right)$ and entropy change $\left(\Delta S^{\circ}\right)$ were obtained by plotting $\ln K_{\mathrm{d}}$ versus $1 / \mathrm{T}$ (SI Figure $\mathrm{S5i})$. At all temperatures, the values of $\mathrm{K}_{\mathrm{d}}$ were in the order $\mathrm{Pb}(\mathrm{II})>\mathrm{Cd}(\mathrm{II})>\mathrm{Cu}(\mathrm{II})$, which indicates that the affinity of EDAR resin for $\mathrm{Pb}$ (II) is higher than for $\mathrm{Cd}(\mathrm{II})$ or $\mathrm{Cu}(\mathrm{II})$. The negative values of Gibbs energy $\left(\Delta G^{\circ}\right)(-1.73$ to $-17.77 \mathrm{~kJ} / \mathrm{mol})$ and positive values of $\Delta H^{\circ}$ for all tested conditions and HMs (SI Table S6) indicate a spontaneous and endothermic adsorption process. The adsorption process is generally considered to involve chemical bonds if the absolute magnitude of $\Delta H^{\circ}$ is $>60 \mathrm{~kJ} / \mathrm{mol}$, and coordination exchange when $\Delta H^{\circ}$ is about $40 \mathrm{~kJ} / \mathrm{mol}$, whereas for van der Waals and hydrophobic 
bonds it is $\leq 10 \mathrm{~kJ} / \mathrm{mol}$ [27]. The absolute values of $\Delta H^{\circ}$ for all the tested HMs were in the range 6.6 to $60 \mathrm{~kJ} / \mathrm{mol}$, suggesting that there is a combination of physisorption and covalent bonding. Furthermore, the positive values of $\Delta S^{\circ}$ indicate that adsorption phenomenon for HMs on EDAR involves an associative mechanism, and that there is increased disorder at the solid-solution interface.

\subsubsection{Effect of Natural Water Matrix}

We further investigated the potential of using EDAR for practical applications by determining its performance with natural waters spiked with $\mathrm{Pb}(\mathrm{II}), \mathrm{Cd}(\mathrm{II})$, or $\mathrm{Cu}(\mathrm{II})$ and adjusting the $\mathrm{pH}$ to 5.0. Results showed that the lake water had a significant effect on HMs adsorption because of its relatively high content of DOC (SI Figure S5j), but overall, these experimental results demonstrate the practical applicability of EDAR for removing HMs from environmental samples.

\subsection{Dynamic Adsorption and Regeneration Studies}

To further investigate its feasibility for practical use, we studied adsorption of $\mathrm{Pb}$ (II), $\mathrm{Cd}(\mathrm{II})$, and $\mathrm{Cu}$ (II) on fixed-bed columns of EDAR. The break-through curves (Figure 3a) indicate that the column performance was less satisfactory for $\mathrm{Cu}$ (II) than for $\mathrm{Pb}$ (II) or $\mathrm{Cd}(\mathrm{II})$ adsorption, and analysis of the behavior of the adsorbent-adsorbate system by the Thomas, Yoon-Nelson, Adams-Bohart models (SI Text S9) showed good fits to the dynamic adsorption data with the Thomas and Yoon-Nelson models with adsorption capacities of $1.64,1.20$, and $0.74 \mathrm{mmol} / \mathrm{g}$ for $\mathrm{Pb}(\mathrm{II}), \mathrm{Cd}(\mathrm{II})$, and $\mathrm{Cu}(\mathrm{II})$, respectively (SI Figure S7 and SI Table S7).

In order to examine its potential for reuse, the EDAR column that had been saturated with $\mathrm{Pb}$ (II) was regenerated with $0.1 \mathrm{M} \mathrm{HCl}$ solution followed by $0.2 \mathrm{M} \mathrm{NaHCO}_{3}$ at $25^{\circ} \mathrm{C}$. Most of the eluted $\mathrm{Pb}$ (II) was concentrated within about 50 bed volume (BV) (Figure 3b). When five consecutive adsorption-regeneration cycles were performed (Figure 3c), the dynamic adsorption capacity decreased progressively to $85.9 \%, 80 \%, 73.0 \%$, and $67.5 \%$ of the initial value. In addition, the stability of the EDAR resin in the solution phase was assessed by monitoring the composition of the leachate, which did not detect styrene, chlorobenzene, xylene, or methacrylic acid.
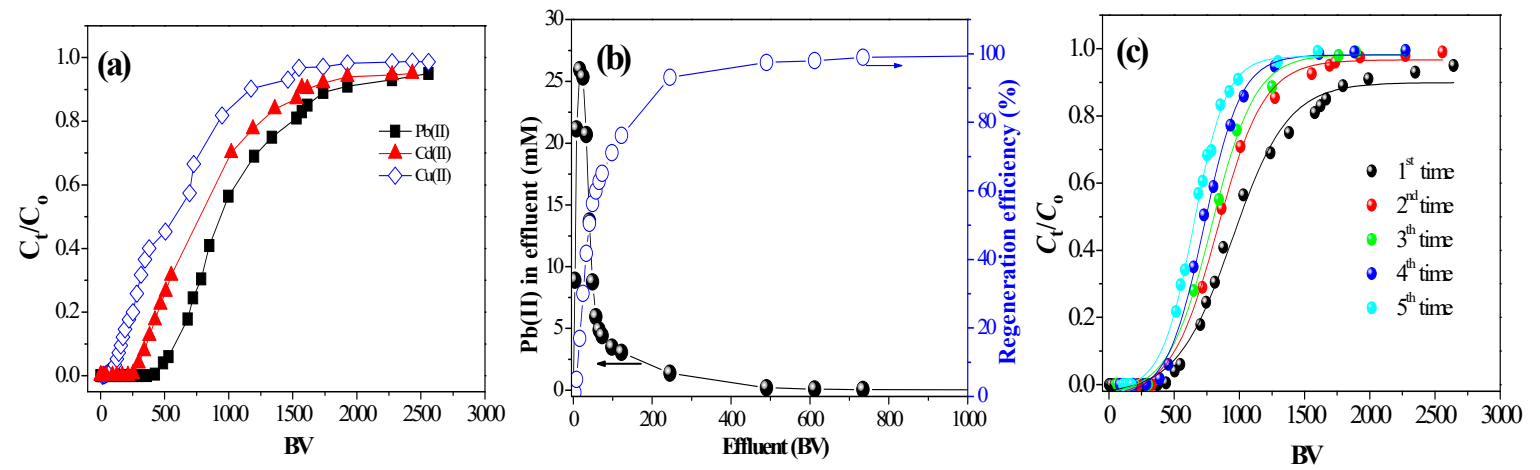

Figure 3. Dynamic adsorption and desorption profiles of $\mathrm{HMs}$ on EDAR at $25^{\circ} \mathrm{C}$. (a) Adsorption breakthrough curves (experimental conditions: [HMs] $=0.5 \mathrm{mM}$, flow rate was $2.0 \mathrm{~mL} / \mathrm{min}$ at $\mathrm{pH}$ 5.0); (b) desorption of $\mathrm{Pb}$ (II) from EDAR column loaded with $1.63 \mathrm{mmol} / \mathrm{g} \mathrm{Pb}$ using $0.1 \mathrm{~mol} / \mathrm{L} \mathrm{HCl}$ with a flow rate of $4 \mathrm{~mL} / \mathrm{min}$, and $7 \mathrm{~h}$ desorption time followed by $0.2 \mathrm{~mol} / \mathrm{L} \mathrm{NaHCO}_{3}$; and (c) breakthrough curves for $\mathrm{Pb}(\mathrm{II})$ on $\mathrm{EDAR}$ that had been subjected to successive regeneration treatments.

\subsection{Interaction Mechanisms and Models}

\subsubsection{Spectroscopic Investigations}

FTIR, X-ray photoelectron spectroscopy (XPS), and electron paramagnetic resonance (EPR) were used to investigate the adsorption interaction mechanisms of HMs with EDAR. The FTIR spectra of EDAR before and after adsorption of $\mathrm{Pb}(\mathrm{II}), \mathrm{Cd}(\mathrm{II})$, and $\mathrm{Cu}(\mathrm{II})$ at $\mathrm{pH} 5.0$ are shown in SI Figure 
S8. The amide II $\left(1549 \mathrm{~cm}^{-1}\right)$ and N-H $\left(3386 \mathrm{~cm}^{-1}\right)$ peaks in EDAR shifted to higher frequencies in EDAR-Pb, EDAR-Cd, and EDAR-Cu, but the residual $\mathrm{HO}-\mathrm{C}=\mathrm{O}$ vibration $\left(1716 \mathrm{~cm}^{-1}\right)$ was not shifted. Thus the $\mathrm{O}=\mathrm{C}-\mathrm{NH}-$ and $\mathrm{N}-\mathrm{H}$ groups of EDAR mainly participate in HMs adsorption [28,29].

The XPS spectra of EDAR before and after HMs adsorption at pH 5.0 are presented in Figure 4 and SI Figure S9. The N1s spectra of EDAR were deconvoluted into three peaks at $399.50 \mathrm{eV}, 400.41 \mathrm{eV}$, and $401.60 \mathrm{eV}$, corresponding to the $\mathrm{N}$ atom in $\mathrm{R}-\mathrm{NH}_{2}, \mathrm{O}=\mathrm{C}-\mathrm{N}-\mathrm{H}$, and $\mathrm{R}-\mathrm{NH}_{3}{ }^{+}$, respectively $[5,30]$. After adsorption of HMs, the energies of the N1s peaks of $\mathrm{R}^{-\mathrm{NH}_{3}}{ }^{+}$and $\mathrm{O}=\mathrm{C}-\mathrm{NH}_{2}{ }^{-}$increased by $0.3 \mathrm{eV}$, whereas those of $\mathrm{R}-\mathrm{NH}_{2}$ were essentially unchanged (Figure $4 \mathrm{e}-\mathrm{h}$ ). This result suggests that $\mathrm{HMs}$ bind to EDAR by displacing $\mathrm{H}^{+}$from $\mathrm{R}-\mathrm{NH}_{3}{ }^{+}$and not to the lone-pair of electrons at $\mathrm{R}^{-} \mathrm{NH}_{2}$ (Figure $4 \mathrm{e}-\mathrm{h}$ ). Deconvolution of the C1s spectra of EDAR produced four peaks with binding energy of 284.60, 286.10, 287.40 , and $288.40 \mathrm{eV}$, which can be assigned to $\mathrm{C}$ atoms in the forms of $\mathrm{C}-\mathrm{C}, \mathrm{C}-\mathrm{O}$ (alcoholic), $\mathrm{N}-\mathrm{C}=\mathrm{O}$ (amide), and $\mathrm{O}-\mathrm{C}=\mathrm{O}$ (carboxylate), respectively [31,32]. After HMs adsorption, the $\mathrm{C} 1$ s binding energy of $-\mathrm{C}=\mathrm{O}$ peaks increased by about $0.2 \mathrm{eV}$ (Figure $4 \mathrm{a}-\mathrm{d}$ ). The $\mathrm{O} 1 \mathrm{~s}$ spectra were deconvoluted into two component peaks at $531.39 \mathrm{eV}$ and $532.89 \mathrm{eV}$, which are mainly associated with the $-\mathrm{C}=\mathrm{O}$ and $\mathrm{C}-\mathrm{O}$ groups. After $\mathrm{HM}$ adsorption, the $\mathrm{O} 1 \mathrm{~s}$ binging energy of the $-\mathrm{C}=\mathrm{O}$ peaks decreased by about $0.1 \mathrm{eV}$ (SI Figure S9), which is consistent with a decrease in electron density on the $\mathrm{O}$ atoms [31]. Consequently, both FTIR and XPS spectra suggest that both $\mathrm{N}$ and $\mathrm{O}(\mathrm{C}=\mathrm{O})$ atoms are involved in the bonding between HMs and EDAR.
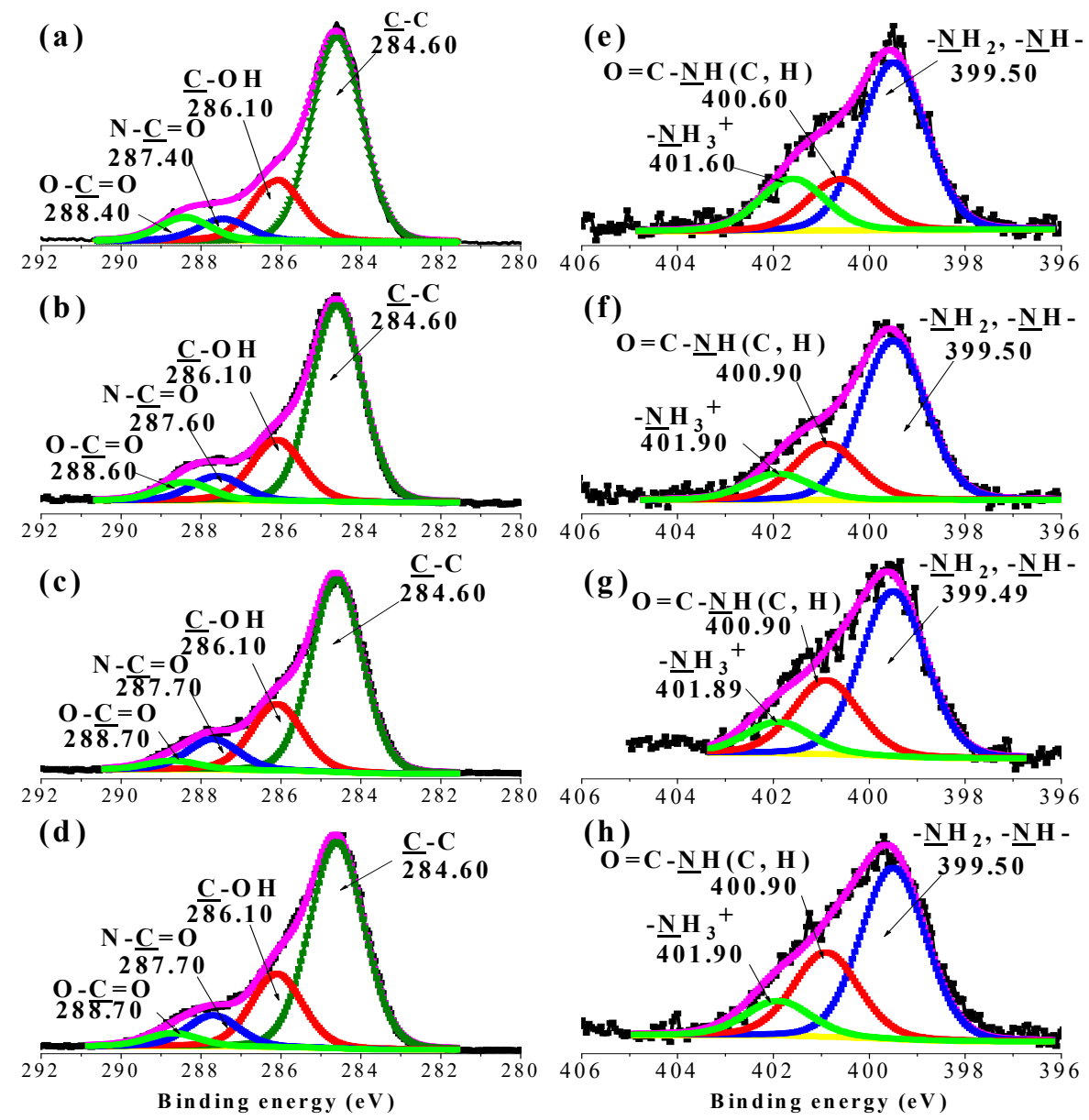

Figure 4. C1s (a-d) and N1s (e-h) X-ray photoelectron spectroscopy of EDAR and their deconvolutions into component peaks before (a and e), and after adsorption of $\mathrm{Pb}$ (II) (b and $\mathbf{f}), \mathrm{Cd}(\mathrm{II})$ ( $\mathbf{c}$ and $\mathbf{g}$ ), and $\mathrm{Cu}(\mathrm{II})$ (d and $\mathbf{h})$.

Since $\mathrm{Cu}(\mathrm{II})$ is paramagnetic, EPR spectroscopy was used to further investigate the coordination environment of $\mathrm{Cu}(\mathrm{II})$ adsorbed on MAR and EDAR at $\mathrm{pH}$ 5.0. The spectrum from the MAR sample 
(Figure 5a) resembles that of the hydrated $\mathrm{Cu}(\mathrm{II})$ ion, whereas the spectrum of $\mathrm{Cu}(\mathrm{II})$-saturated EDAR (Figure $5 b$ ) corresponds to copper in complexes with tetragonal symmetry. This spectrum is broadened by dipolar interactions between neighboring $\mathrm{Cu}$ (II) ions, which makes it difficult to determine the spectral parameters accurately, but adsorbing a lower amount of $\mathrm{Cu}$ gave a better resolved spectrum (Figure 5c). A $2^{\text {nd }}$ derivative recording of this sample showed the presence of some ${ }^{14} \mathrm{~N}$ superhyperfine structure (shfs) (Figure $5 \mathrm{~d}$ ), which is similar to that previously reported for a N-rich sample of EDAR [33]. This shfs is not sufficiently well resolved for direct determination of the number of nitrogen atoms bound to the copper, but Liu et al [33] reported that the $\mathrm{g}_{/ /}$- and $\mathrm{A}_{/ /}(\mathrm{Cu})$-values for copper adsorbed on a similar resin sample are consistent with the copper being coordinated to four nitrogen atoms.



Figure 5. $1^{\text {st }}$ derivative EPR spectra at room temperature $\left(\sim 25^{\circ} \mathrm{C}\right)$ of $\mathrm{Cu}(\mathrm{II})$ adsorbed on (a) MAR, and (b) EDAR. Spectra from lower adsorption levels of $\mathrm{Cu}(\mathrm{II})$ on EDAR are also shown as (c) $1^{\text {st }}$ derivative, and (d) 2nd derivative recordings.

\subsubsection{Interaction Models}

The possible modes of coordination of HMs to EDAR was further investigated using quantum chemical calculations with $\mathrm{Pb}(\mathrm{II})$ as the target metal. These calculations used three dimeric structures as models, namely complete amination (aa), partial amination (ab), and non-amination (bb). It should 
be noted that steric effects in the polymer on adsorption of HMs was not considered and the focus was only on the interaction between the dimer structure of EDAR and $\mathrm{Pb}$. Optimized structures of possible EDAR-Pb(II) complexes are shown in Figure 6 and SI Figure S10, in which H1-H3 are the hypothetical initial structures of aa- $\mathrm{Pb}(\mathrm{II}), \mathrm{H} 4-\mathrm{H} 6$ are those for ab- $\mathrm{Pb}(\mathrm{II})$, and $\mathrm{H} 7$ is that for $\mathrm{bb}-\mathrm{Pb}(\mathrm{II})$, and $\mathrm{O}_{1}, \mathrm{O}_{2}$, $\mathrm{O}_{3}$ are the optimized structures for aa- $\mathrm{Pb}(\mathrm{II})$, ab- $\mathrm{Pb}(\mathrm{II}), \mathrm{bb}-\mathrm{Pb}(\mathrm{II})$, respectively.


Figure 6. Dimeric structures used to simulate potential basic units of EDAR polymers for coordination with $\mathrm{Pb}$ (II) (for clarity, hydrogen atoms are omitted from all structures).

For $\mathrm{Pb}(\mathrm{II})$ adsorption, the $\Delta \mathrm{E}$ values for the models aa- $\mathrm{Pb}$ (II), ab-Pb(II) and bb- $\mathrm{Pb}$ (II) were -1116.41 , -837.99 , and $-663.79 \mathrm{~kJ} / \mathrm{mol}$, respectively, thus showing a preference of $\mathrm{Pb}$ (II) for $\mathrm{N}$ compared to $\mathrm{O}$ coordination. Although the bonding to the actual resin is complicated by other factors, such as the steric arrangements of the functional groups, these results strongly support the experimental observation that amination of MAR can significantly improve its adsorption capacity for HMs. Normally, bond length in functional groups will lengthen when coordinated to metals, and the lengths of bonds coordinated to $\mathrm{Pb}$, namely $\mathrm{C} 8=\mathrm{O} 19, \mathrm{C} 11-\mathrm{N} 12, \mathrm{C} 14=\mathrm{O} 28$, and C17-N18 were increased by $0.042 \AA, 0.045 \AA, 0.037 \AA$, and $0.029 \AA$, respectively (SI Table S8). These results also confirm the quadridentate configuration of $\mathrm{Pb}$ (II) adsorbed on EDAR, and thus its resemblance to the $\mathrm{Cu}$ (II) coordination revealed by the EPR measurements.

\section{Conclusions}

The novel resin EDAR with aminated functional groups exhibited excellent adsorption properties for the $\mathrm{HM}$ ions $\mathrm{Pb}(\mathrm{II}), \mathrm{Cd}(\mathrm{II})$, and $\mathrm{Cu}(\mathrm{II})$, and compared favorably with many commercial resins. Adsorption was $\mathrm{pH}$-dependent and most effective for the range 4.0-6.0. The adsorption capacity was in the order $\mathrm{Pb}(\mathrm{II})>\mathrm{Cd}$ (II) $>\mathrm{Cu}$ (II) in single, and competitive systems. Apart from $\mathrm{Cd}-\mathrm{Cu}$ and $\mathrm{Cd}-\mathrm{Pb}-\mathrm{Cu}$ systems, the multicomponent systems were fitted well by the Langmuir competitive model. Various spectroscopic investigations showed that both $\mathrm{N}$ and $\mathrm{O}$ atoms in EDAR are involved in the coordination of $\mathrm{Pb}(\mathrm{II}), \mathrm{Cd}(\mathrm{II})$, and $\mathrm{Cu}(\mathrm{II})$, whereas quantum chemical calculations indicated that coordination to the amine groups was energetically the most favorable arrangement. Overall, the combination of thermodynamic and spectroscopic results with quantum mechanics calculations indicates that both chemical bonding and electrostatic processes are involved in HM adsorption on EDAR. In addition, the HMs could be successfully removed from the EDAR with $0.1 \mathrm{M} \mathrm{HCl}$, and the resin regenerated for further use by treating with $\mathrm{NaHCO}_{3}$ solutions. Finally, EDAR was applied successfully to the removal of HMs from natural waters, and further studies to validate its performance in various practical applications are currently underway. Consequently, we believe that the rosin-based resin has great potential to replace of the petroleum-derived resins that are currently used.

Supplementary Materials: The following are available online at http://www.mdpi.com/2073-4360/11/6/969/s1, Figure S1. Effect of adsorbent dosage on HMs adsorption on EDAR (a) and removal from solution (b). Experimental

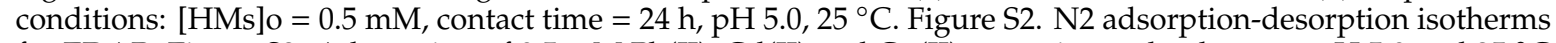
for EDAR. Figure S3. Adsorption of $0.5 \mathrm{mM} \mathrm{Pb}(\mathrm{II}), \mathrm{Cd}(\mathrm{II})$ and $\mathrm{Cu}(\mathrm{II})$ on various adsorbents at $\mathrm{pH} 5.0$ and $25^{\circ} \mathrm{C}$ using $1.0 \mathrm{~g} / \mathrm{L}$ adsorbent dosage. Figure $\mathrm{S} 4$. Experimental results for the competitive adsorption of $\mathrm{Pb}, \mathrm{Cd}$, and $\mathrm{Cu}$ in binary systems presented in the linear form of the Langmuir competitive model. Figure S5. Effect of 
different parameters on the adsorption of $\mathrm{Pb}(\mathrm{II}), \mathrm{Cd}(\mathrm{II})$ and $\mathrm{Cu}(\mathrm{II})$ by EDAR. (a) solution $\mathrm{pH}$; (b) ionic strength; (c) $\mathrm{Ca}$ (II) and $\mathrm{Mg}$ (II); (d) HA. (e) contact time; (f) Pseudo-second-order; (g) Intra-particle diffusion model; (h) temperature; (i) Plots of $l n k d$ versus $1 / \mathrm{T}$ for the adsorption of $\mathrm{Pb}(\mathrm{II}), \mathrm{Cd}$ (II) and $\mathrm{Cu}$ (II) by EDAR; (j) different water matrixes. Experimental conditions: $[\mathrm{HMs}]=0.5 \mathrm{mM}$ (except for adsorption isotherm test), [EDAR dosage] = $1.0 \mathrm{~g} / \mathrm{L}, \mathrm{pH} 5.0$ (except for $\mathrm{pH}$ test), $25^{\circ} \mathrm{C}$ (except for temperature test). Figure S6. Variation in zeta potential of EDAR and MAR as a function of $\mathrm{pH}$. Figure $\mathrm{S} 7$. Comparison of experimental curves for adsorption of $\mathrm{Pb}(\mathrm{II})$, $\mathrm{Cd}(\mathrm{II})$, and $\mathrm{Cu}(\mathrm{II})$ on EDAR with predicted breakthrough curves obtained from the Thomas, Adams Bohart, and Yoon-Nelson models. Figure S8. FTIR spectra of EDAR before and after adsorption of $\mathrm{Pb}(\mathrm{II}), \mathrm{Cd}(\mathrm{II})$, and $\mathrm{Cu}(\mathrm{II})$. Figure S9. XPS O1s spectra of EDAR before (a) and after adsorption of $\mathrm{Pb}(\mathrm{II})(\mathrm{b}), \mathrm{Cd}(\mathrm{II})$ (c), and $\mathrm{Cu}(\mathrm{II})$ (d). Figure S10. Initial geometries (H1-H7) used for calculations of $\mathrm{Pb}(\mathrm{II})$ coordination to EDAR, and the corresponding optimized coordination geometries (O1-O3). Table S1. Physicochemical properties of the adsorbents used in the study. Table S2. Main characteristics of the natural water samples used in this study. Table S3. Adsorption isotherm model constants for single systems at $25^{\circ} \mathrm{C}$. Table S4. Comparison of adsorption capacities of various adsorbents for HMs at $\mathrm{pH}$ 5.0. Table S5. Kinetic parameters for the adsorption of $\mathrm{Pb}(\mathrm{II}), \mathrm{Cd}(\mathrm{II})$, and $\mathrm{Cu}$ (II) on EDAR. Table S6. Thermodynamic parameters for the adsorption of HMs on EDAR (0.5 mM HMs). Table S7. Parameters for the Thomas, Adams-Bohart, and Yoon-Nelson dynamic adsorption models fitted for Pb(II), Cd(II), and $\mathrm{Cu}(\mathrm{II})$. Table S8. Changes in lengths of selected bonds in EDAR model aa as a result of complexation with $\mathrm{Pb}$ (II) (in $\mathrm{A}^{\circ}$ ).

Author Contributions: Conceptualization, S.L.; Data curation, W.H.; Formal analysis, Y.M.; Investigation, Y.M.; Methodology, J.J.; Project administration, F.L. and S.L.; Resources, F.L.; Software, K.D.; Supervision, S.L. and X.T.; Visualization, W.H.; Writing—original draft, W.H.; Writing—review \& editing, S.L. and B.A.G.

Acknowledgments: This work was supported by the National Key R D Program of China (Grant Nos. 2016YFD0600804), National Natural Science Foundation of China (Grant Nos. 21667005, 21567004, and 21367004), Guangxi Natural Science Foundation (2016GXNSFCA380009), Specific Research Project of Guangxi for Researches Bases and Talents (AD18126005), and Young Scholar Innovation Team of Guangxi University for Nationalities (2016 and YCSW2018121). We thank Associate Zhenglong Wu and Jing Tian for assistance with XPS analysis.

Conflicts of Interest: The authors declare no conflict of interest.

\section{References}

1. Nriagu, J.O.; Pacyna, J.M. Quantitative assessment of worldwide contamination of air, water and soils by trace metals. Nature 1988, 333, 134-139. [CrossRef] [PubMed]

2. Ling, L.L.; Liu, W.J.; Zhang, S.; Jiang, H. Magnesium oxide embedded nitrogen self-doped biochar composites: Fast and high-efficiency adsorption of heavy metals in an aqueous solution. Environ. Sci. Technol. 2017, 51, 10081-10089. [CrossRef] [PubMed]

3. Feng, X.; Fryxell, G.E.; Wang, L.Q.; Kim, A.Y.; Liu, J.; Kemner, K.M. Functionalized monolayers on ordered mesoporous supports. Science 1997, 276, 923-926. [CrossRef]

4. Wingenfelder, U.; Hansen, C.; Furrer, G.; Schulin, R. Removal of heavy metals from mine waters by natural zeolites. Environ. Sci. Technol. 2005, 39, 4606-4613. [CrossRef]

5. Liu, H.J.; Yang, F.; Zheng, Y.M.; Kang, J.; Qu, J.H.; Chen, J.P. Improvement of metal adsorption onto chitosan/Sargassum sp. composite sorbent by an innovative ion-imprint technology. Water Res. 2011, 45, 145-154. [CrossRef] [PubMed]

6. Pan, B.J.; Zhang, W.M.; Pan, B.C.; Qiu, H.; Zhang, Q.R.; Zhang, Q.X.; Zheng, S.R. Efficient removal of aromatic sulfonates from wastewater by a recyclable polymer: 2-naphthalene sulfonate as a representative pollutant. Environ. Sci. Technol. 2008, 42, 7411-7416. [CrossRef] [PubMed]

7. Tran, H.N.; Chao, H.P. Adsorption and desorption of potentially toxic metals on modified biosorbents through new green grafting process. Environ. Sci. Pollut. 2018, 25, 12808-12820. [CrossRef] [PubMed]

8. Tran, H.N.; Huang, F.C.; Lee, C.K.; Chao, H.P. Activated carbon derived from spherical hydrochar functionalized with triethylenetetramine: Synthesis, characterizations, and adsorption application. Green Process. Synth. 2017, 6, 565-576. [CrossRef]

9. Chen, T.; Liu, F.; Ling, C.; Gao, J.; Xu, C.; Li, L.; Li, A. Insight into highly efficient coremoval of copper and $p$-nitrophenol by a newly synthesized polyamine chelating resin from aqueous media: Competition and enhancement effect upon site recognition. Environ. Sci. Technol. 2013, 47, 13652-13660. [CrossRef] [PubMed]

10. Gupta, V.; Singh, P.; Rahman, N. Adsorption behavior of $\mathrm{Hg}(\mathrm{II}), \mathrm{Pb}(\mathrm{II})$, and $\mathrm{Cd}(\mathrm{II})$ from aqueous solution on Duolite C-433: A synthetic resin. J. Colloid Interface Sci. 2004, 275, 398-402. [CrossRef] 
11. Pan, B.; Zhang, Q.; Meng, F.; Li, X.; Zhang, X.; Zheng, J.; Zhang, W.; Pan, B.; Chen, J. Sorption enhancement of aromatic sulfonates onto an aminated hyper-cross-linked polymer. Environ. Sci. Technol. 2005, 39, 3308-3313. [CrossRef] [PubMed]

12. Agents, V. Auxiliary Materials, Kirk-Othmer, Encyclopedia of Chemical Technology; Wiley Interscience: New York, NY, USA, 1982.

13. Franz, G.; Sheldon, R.A. Chemical Reactions/Oxidation. In Ullmann's Encyclopedia of Industrial Chemistry; Bailey, J.E., Ed.; John Wiley \& Sons Inc.: Weinheim, Germany, 2007; pp. 15-33.

14. Li, P.; Wang, T.; Lei, F.; Tang, P.; Tan, X.; Liu, Z.; Shen, L. Rosin-based molecularly imprinted polymers as the stationary phase in high-performance liquid chromatography for selective separation of berberine hydrochloride. Polym. Int. 2014, 63, 1699-1706. [CrossRef]

15. Ma, Q.Q.; Liu, X.Q.; Zhang, R.Y.; Zhu, J.; Jiang, Y.H. Synthesis and properties of full bio-based thermosetting resins from rosin acid and soybean oil: The role of rosin acid derivatives. Green Chem. 2013, 15, 1300-1310. [CrossRef]

16. Lee, J.S.; Hong, S.I. Synthesis of acrylic rosin derivatives and application as negative photoresist. Eur. Polym. J. 2002, 38, 387-392. [CrossRef]

17. Gao, J.; Liu, F.Q.; Ling, P.P.; Lei, J.T.; Li, L.J.; Li, C.H.; Li, A.M. High efficient removal of Cu(II) by a chelating resin from strong acidic solutions: Complex formation and DFT certification. Chem. Eng. J. 2013, 222, 240-247. [CrossRef]

18. Yang, L.Q.; Li, Y.F.; Wang, L.Y.; Zhang, Y.; Ma, X.J.; Ye, Z.F. Preparation and adsorption performance of a novel bipolar PS-EDTA resin in aqueous phase. J. Hazard. Mater. 2010, 180, 98-105. [CrossRef]

19. Song, S.H.; Ji, C.N.; Wang, M.; Wang, C.R.; Sun, C.M.; Qu, R.J.; Wang, C.H.; Chen, H. Adsorption of silver(I) from aqueous solution by chelating resins with 3-aminopyridine and hydrophilic spacer arms: Equilibrium, kinetic, thermodynamic, and mechanism studies. J. Chem. Eng. Data 2011, 56, 1001-1008. [CrossRef]

20. Song, L.Z.; Zhao, X.D.; Fu, J.; Wang, X.L.; Sheng, Y.P.; Liu, X.W. DFT investigation of Ni(II) adsorption onto MA-DTPA/PVDF chelating membrane in the presence of coexistent cations and organic acids. J. Hazard. Mater. 2012, 199, 433-439. [CrossRef]

21. Fu, L.C.; Liu, F.Q.; Ma, Y.; Tao, X.W.; Ling, C.; Li, A.M.; Shuang, C.D.; Li, Y. High-efficient technique to simultaneous removal of $\mathrm{Cu}(\mathrm{II}), \mathrm{Ni}(\mathrm{II})$ and tannic acid with magnetic resins: Complex mechanism behind integrative application. Chem. Eng. J. 2015, 263, 83-91. [CrossRef]

22. Jing, X.S.; Liu, F.Q.; Yang, X.; Ling, P.P.; Li, L.J.; Long, C.; Li, A.M. Adsorption performances and mechanisms of the newly synthesized $N, N^{\prime}$-di(carboxymethyl) dithiocarbamate chelating resin toward divalent heavy metal ions from aqueous media. J. Hazard. Mater. 2009, 167, 589-596. [CrossRef]

23. Frisch, M.J.; Trucks, G.W.; Schlegel, H.B.; Scuseria, G.E.; Robb, M.A.; Cheeseman, J.R.; Scalmani, G.; Barone, V.; Mennucci, B.; Petersson, G.A.; et al. Gaussian 09 Revision D.01; Gaussian, Inc.: Wallingford, CT, USA, 2009.

24. Sing, K.S.W.; Everett, D.H.; Haul, R.A.W.; Moscou, L.; Pierotti, R.A.; Rouquerol, J.; Siemieniewska, T. Reporting physisorption data for gas/solid systems with special reference to the determination of surface area and porosity. Pure Appl. Chem. 1982, 54, 2201-2218. [CrossRef]

25. Sheindorf, C.; Rebhun, M.; Sheintuch, M. A Freundlich-type multicomponent isotherm. J. Colloid Interface Sci. 1981, 79, 136-142. [CrossRef]

26. Baes, C.F., Jr.; Mesmer, R.E. The Hydrolysis of Cations; Wiley-Interscience: New York, NY, USA, 1976.

27. Liu, S.G.; Ding, Y.Q.; Li, P.F.; Diao, K.S.; Tan, X.C.; Lei, F.H.; Zhan, Y.H.; Li, Q.M.; Huang, B.; Huang, Z.Y. Adsorption of the anionic dye Congo red from aqueous solution onto natural zeolites modified with N,N-dimethyl dehydroabietylamine oxide. Chem. Eng. J. 2014, 248, 135-144. [CrossRef]

28. Kaşgöz, H.; Özgümüş, S.; Orbay, M. Modified polyacrylamide hydrogels and their application in removal of heavy metal ions. Polymer 2003, 44, 1785-1793. [CrossRef]

29. Shubha, K.P.; Raji, C.; Anirudhan, T.S. Immobilization of heavy metals from aqueous solutions using polyacrylamide grafted hydrous tin (IV) oxide gel having carboxylate functional groups. Water Res. 2001, 35, 300-310. [CrossRef]

30. Jin, L.; Bai, R.B. Mechanisms of lead adsorption on chitosan/PVA hydrogel beads. Langmuir 2002, 18, 9765-9770. [CrossRef]

31. Moulder, J.F.; Stickle, W.F.; Sobol, P.E.; Bomben, K.D. Handbook of X-ray Photoelectron Spectroscopy; Perkin-Elmer Corp.: Eden Prairie, MN, USA, 1992. 
32. Lim, S.F.; Zheng, Y.M.; Zou, S.W.; Chen, J.P. Characterization of copper adsorption onto an alginate encapsulated magnetic sorbent by a combined FTIR, XPS and mathematical modeling study. Environ. Sci. Technol. 2013, 42, 2551-2556. [CrossRef]

33. Liu, S.G.; Li, Z.Y.; Diao, K.S.; Huang, W.T.; Wang, J.; Deng, W.; Lei, F.H.; Goodman, B.A. Direct identification of speciation of $\mathrm{Cu}(\mathrm{II})$ adsorbed on rosin derived resins using electron paramagnetic resonance (EPR) spectroscopy. Chemosphere 2018, 210, 789-794. [CrossRef]

(c)

(C) 2019 by the authors. Licensee MDPI, Basel, Switzerland. This article is an open access article distributed under the terms and conditions of the Creative Commons Attribution (CC BY) license (http://creativecommons.org/licenses/by/4.0/). 